\title{
Novel mutations in the gene SALL4 provide further evidence for acro-renal-ocular and Okihiro syndromes being allelic entities, and extend the phenotypic spectrum
}

\author{
W Borozdin, M J Wright, R C M Hennekam, M C Hannibal, Y J Crow, T E Neumann, J Kohlhase
}

J Med Genet 2004;41:e102 (http://www.jmedgenet.com/cgi/content/full/41/8/e102). doi: 10.1136/jmg.2004.019505

T he SALL genes, similar to the Drosophila gene spalt, encode likely zinc finger transcription factors. In humans, four such genes have been identified to date. Mutations in the gene SALL1 on chromosome 16q12.1 have been associated with Townes-Brocks syndrome and related phenotypes, $^{23}$ and mutations in the gene SALL4 have been shown to be causative in patients with Okihiro syndrome. ${ }^{45}$ $S A L L 2^{6}$ and $S A L L 3^{7}$ remain to be associated with human disease.

We previously reported frameshift and nonsense mutations in SALL4 in five of eight families segregating the Okihiro syndrome phenotype. ${ }^{5}$ A further report $^{4}$ identified two frameshift mutations and one nonsense mutation in three affected kindreds, including the family reported by Okihiro et al. ${ }^{8}$ In a recent study of patients with a clinical diagnosis of Holt-Oram syndrome, one additional frameshift mutation and an unclear missense change were reported from a family who turned out to have Okihiro syndrome rather than HoltOram. ${ }^{9}$ Furthermore, we reported one previously identified and three novel SALL4 mutations in patients originally diagnosed as having either Holt-Oram syndrome (later revised to Okihiro syndrome based on the observation of a Duane anomaly in at least one of the affected family members in each family), acro-renal-ocular syndrome, or Holt-Oram syndrome versus thalidomide embryopathy. ${ }^{10}$ While our findings suggested that acro-renal-ocular syndrome and Okihiro syndrome are allelic, evidence so far has come only from one family in which no gross structural eye defects were seen. ${ }^{11}$ In order to further substantiate our findings we sought to perform mutation analysis in additional patients diagnosed with acro-renal-ocular syndrome, especially those who presented with structural eye defects. We were also interested in extending our studies to further patients with Okihiro syndrome in order to allow a genotype-phenotype correlation. Here we report five novel SALL4 mutations from five unrelated families, three nonsense and two frameshift mutations. Previous clinical diagnosis was Holt-Oram syndrome, Okihiro syndrome, or Townes-Brocks syndrome, in each of three families, and acrorenal-ocular syndrome in a further two families.

\section{METHODS}

Patients

Venous blood was collected from patients and unaffected relatives after obtaining their informed consent.

\section{Genetic analysis}

Genomic DNA was prepared from peripheral lymphocytes by routine procedures. Mutation analysis of SALL4 exons 1-4 (complete coding region) was performed as described. Mutations were confirmed by a second, independent PCR, and direct sequencing of amplicons. In one family, the exact mutation was not readable from the direct sequencing

\section{Key points}

- Okihiro syndrome results from mutations in the gene SALL4 on chromosome 20q13.13-13.2. Previously, 13 different mutations have been found in patients with Okihiro syndrome as well as in patients with a primary diagnosis of Holt-Oram syndrome, acro-renal-ocular syndrome, or thalidomide embryopathy.

- Patients diagnosed with acro-renal-ocular syndrome show markedly different involvement of the eye, ranging from Duane anomaly to structural eye defects.

- We report five novel SALL4 mutations in five unrelated families, among them a family previously reported as exhibiting acro-renal-ocular syndrome with the index patient showing structural eye defects but no Duane anomaly. This provides further proof that Okihiro and acro-renal-ocular syndromes are allelic conditions.

- SALL4 mutations can also be associated with severe heart defects, that is, tetralogy of Fallot. Our results therefore extend the phenotypic spectrum of SALL4 mutations.

electropherogram, although an overlap of two different alleles was visible. Therefore, the PCR product was subcloned into pGEM-T (Promega), and plasmids from three different bacterial colonies were sequenced, all harbouring the mutated allele.

\section{CASE REPORTS}

In family 1 , the affected child (fig 1A, II.l; fig 3B-D) presented with anal stenosis, tetralogy of Fallot, sacrovertebral fusion, and bilateral radial ray abnormalities with complete absence of the left radius/thumb and hypoplasia of the right thumb. Both ears were mildly dysplastic. Bilateral talipes were seen. Renal ultrasound was normal. His father has bilateral triphalangeal thumbs (fig 3A). Primary diagnosis was VACTERL (vertebral, anal, cardiac, renal, and limb anomalies present) versus Townes-Brocks syndrome.

In family 2 of Kosovo origin (fig 1B), five members were diagnosed as being affected with Holt-Oram syndrome. Any consanguinity was denied. DNA was available only from the index patient (II.2). This patient (fig 3E and F) is a 39 year old man who shows malformations of all four limbs: mesomelic shortening of the forearms (left more than right), incomplete extension of the left elbow, radial deviation of both hands (left more than right), absence of the left thumb, a hypoplastic right thumb, contractures of fingers II, IV, and $\mathrm{V}$ on the right, on the left side a shortened lower leg $(-4 \mathrm{~cm})$ with syndactyly II/III and III/IV of toes, and bilateral club 
A
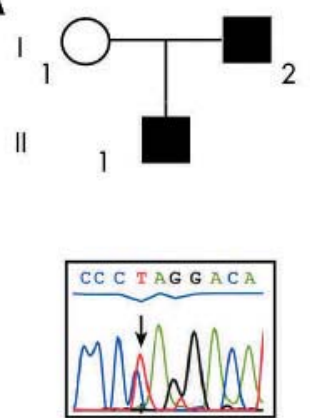

c. $496 \mathrm{C}>\mathrm{T}$

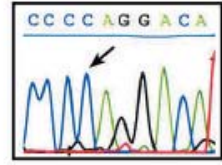

c. 496 wt

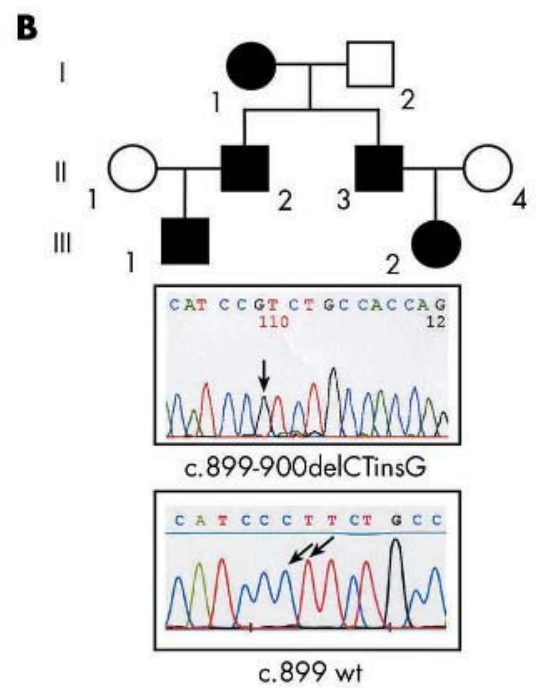

C
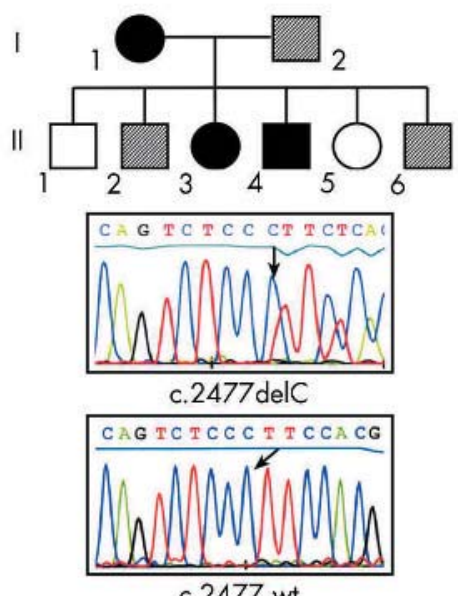

D
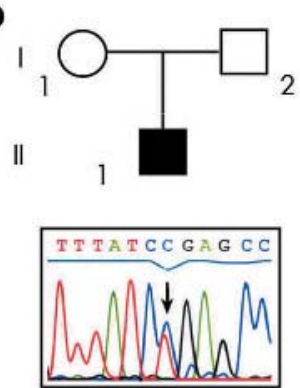

c. $2491 \mathrm{C}>\mathrm{T}$

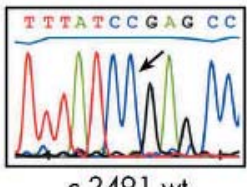

$\mathbf{E}$
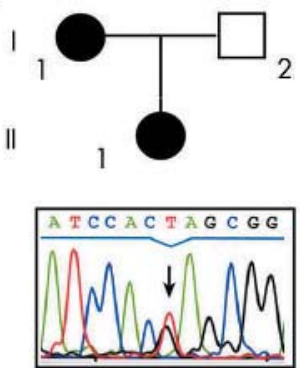

c. $2665 \mathrm{G}>\mathrm{T}$

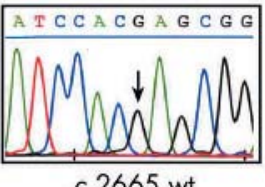

Figure 1 Novel SALL4 mutations identified in five families. For phenotypic features see table 1 and fig 3. (A) Mutation c.496C $>$ T found in the index patient II. 1 and his father II.2. Primary diagnosis was VACTERL versus Townes-Brocks syndrome. (B) Family 2, showing c.899-900delCTinsG mutation in the only available family member II.2. Primary diagnosis was Holt-Oram syndrome. The electropherogram of the mutation is derived from sequencing of the subcloned SALL4 fragment, therefore heterozygosity is not visible here. (C) Family 3, reported as an example of acro-renal-ocular syndrome. ${ }^{12}$ The c. 2477 delC mutation was found in the index patient II. 4 (the only family member available). (D) Family 4, demonstrating c. $2491 \mathrm{C}>\mathrm{T}$ nonsense mutation associating with the affected phenotype. Primary diagnosis was Okihiro syndrome. (E) Family 5, demonstrating c.2665G $>T$ nonsense mutation segregating with the affected phenotype. Primary diagnosis was Holt-Oram syndrome versus acro-renal-ocular syndrome.

feet. X-ray examinations were refused. He suffers from renal disease (unspecified) but a heart defect could be excluded. On ophthalmologic examination eye movements were normal. His son (III.1) was delivered after uneventful pregnancy. At birth a large perimembranous VSD, a dextro-position of the left kidney, and radial deviation of both hands were noted. Up to the current age of 5 years growth parameters (length, weight, head circumference) were normal. Repeated ophthalmologic examinations excluded a Duane anomaly. Both subjects (II.2 and III.1) were clinically examined by one of the authors. The mother of II.2 was reported to have bilateral shortening of the forearms, radial deviation of both hands, and bilateral hypoplastic thumbs. No heart defect is known. Her second son (II.3) has radial deviation of both hands, but apparently no other major malformations. His daughter (III.2) was reported to have an unilateral shortening of one forearm and a radial deviation of both hands. No heart defect or eye movement abnormality is known.

Family 3 (fig 1C) was reported as an example of acro-renalocular syndrome. ${ }^{12}$ The index patient presented with thumb aplasia on the left and hypoplasia on the right hand, crossed renal dystopia, cataract, iris coloboma, left choroideal coloboma involving the optical nerve, strabismus, nystagmus, bilateral microphthalmia, and microcornea. His mother showed only hypoplasia of the left thumb, whereas the sister had severe upper limb malformations with aplasia of both 
Table 1 Phenotypic features

\begin{tabular}{|c|c|c|c|c|c|c|c|c|}
\hline Patient & Eyes & Arms & Ears & Hearing & Kidneys & Feet & Heart & Other \\
\hline \multicolumn{9}{|c|}{ Family 1} \\
\hline 1.2 & $\mathrm{~N}$ & Bil. triphalangeal thumbs & $\mathrm{N}$ & NR & NR & $\mathrm{N}$ & NR & NR \\
\hline II. 1 & $\mathrm{~N}$ & $A T+A R(L), H P L T(R)$ & Mildly dysplastic & $\mathrm{N}$ & $\mathrm{N}$ & Bil. talipes & TOF & $\begin{array}{l}\text { Anal stenosis, } \\
\text { sacrovertebral } \\
\text { fusion }\end{array}$ \\
\hline \multicolumn{9}{|c|}{ Family 2} \\
\hline 1.1 & $\mathrm{~N}$ & $\begin{array}{l}\text { Bil. HPLT, bil. shortening of } \\
\text { forearms }\end{array}$ & NR & NR & NR & NR & NR & NR \\
\hline$\| .2$ & $\mathrm{~N}$ & $\begin{array}{l}\text { Mesomelic shortening of forearms } \\
(L>R), A T+A R(L), H P L T(R), \\
\text { contractures of } d \text { II, IV, V (R) }\end{array}$ & $\mathrm{N}$ & $\mathrm{N}$ & $\begin{array}{l}\text { Renal } \\
\text { disease } \\
\text { (not specified) }\end{array}$ & $\begin{array}{l}\text { Bil. club foot } \\
\text { syndactyly II/III } \\
\text { ) and III/IV }\end{array}$ & NR & $\begin{array}{l}\text { Short lower leg } \\
\text { (L) }\end{array}$ \\
\hline 11.3 & $\mathrm{~N}$ & Radial deviation of both hands & NR & NR & NR & NR & NR & NR \\
\hline III. 1 & $\mathrm{~N}$ & Radial deviation of both hands & $\mathrm{N}$ & $\mathrm{N}$ & $\mathrm{R}$ pos. (L) & $\mathrm{N}$ & VSD & $\mathrm{N}$ \\
\hline III.2 & $\mathrm{N}$ & $\begin{array}{l}\text { Radial deviation of both hands, } \\
\text { unilat. shortening of forearm }\end{array}$ & NR & NR & NR & NR & NR & NR \\
\hline \multicolumn{9}{|c|}{ Family 3} \\
\hline 1.1 & $\mathrm{~N}$ & HPLT (L) & $\mathrm{N}$ & NR & NR & NR & NR & NR \\
\hline II.3 & $\begin{array}{l}\text { Struct. defects, } \\
\text { strab., nyst. }\end{array}$ & HPLT (R), AT (L) & $\mathrm{N}$ & $N$ & $\begin{array}{l}\text { Crossed } \\
\text { dystopia }\end{array}$ & $N$ & $N$ & \\
\hline II.4 & $\mathrm{N}$ & $\begin{array}{l}\text { Bil. AT, AR, AU, short humerus } \\
\text { (L) }\end{array}$ & $\mathrm{N}$ & $\mathrm{N}$ & NR & NR & NR & \\
\hline \multicolumn{9}{|c|}{ Family 4} \\
\hline 11.1 & Bil. DA & Bil. AT+AR & $\begin{array}{l}\text { Slit-like openings } \\
\text { of EAM }\end{array}$ & $\mathrm{N}$ & $\mathrm{N}$ & $\mathrm{N}$ & $\mathrm{N}$ & $\begin{array}{l}\text { Bil. epicanthic } \\
\text { folds }\end{array}$ \\
\hline \multicolumn{9}{|c|}{ Family 5} \\
\hline 1.1 & Bil. DA & $\begin{array}{l}\text { HPLT }(L), A T(R), \text { HPL of radius } \\
\text { and ulna (R) }\end{array}$ & $\mathrm{N}$ & $\mathrm{N}$ & Fused pelvic & $\mathrm{N}$ & $\mathrm{N}$ & \\
\hline II.1 & DA (L) & $\begin{array}{l}\text { HPLT (R), AT (L), HPL of radius } \\
\text { and ulna } L>R\end{array}$ & $\mathrm{~N}$ & $\mathrm{~N}$ & Low pos. $\mathrm{R}$ & $\mathrm{N}$ & VSD & \\
\hline
\end{tabular}

AR, absent radius/radii; AT, absent thumb(s); Bil., bilateral; DA, Duane anomaly; EAM, external auditory meatus; HPL, hypoplasia; HPLT, hypoplasia of thumb(s); L, left; N, normal; NR, no abnormality reported; Nyst., nystagmus, Pos., position; R, right; Strab., strabismus; TOF, tetralogy of Fallot; VSD, ventricular septal defect. Structural eye defects in 11.3 (family 3 ) are: cataract, iris and chorioideal coloboma, microphthalmia, and microcornea.

thumbs, radii, and ulnae. In addition, the left humerus was short. The father and two brothers of the index patient were reported to have postaxial polydactyly, assumed to be unrelated to the features observed in the clearly affected members.

The index patient in family 4 (fig 1D, II.1) represents a sporadic case of Okihiro syndrome. He has bilateral aplasia of thumbs and radius as well as a bilateral Duane anomaly. He was also found to have slit like external ear canals and bilateral epicanthic folds.

In family 5 (fig $1 E$, fig $3 G$ and $H$ ), two members are affected. The daughter presented with Duane anomaly of the left eye, thumb aplasia on the left, and a hypoplastic thumb on the right side. Radius and ulna on the left side were hypoplastic while the radius on the right was also relatively short. In addition, she had a low lying kidney on the right, nearly in the pelvis, and a small apical muscular VSD. Her mother had bilateral Duane anomaly and strabismus requiring surgery, a hypoplastic left thumb with absent left first metacarpal, aplasia of the right thumb with hypoplastic radius and ulna, and a fused pelvic kidney.

\section{RESULTS}

SALL4 mutation analysis was carried out in one patient (family 1 , figs 1 and 3 ) in whom VACTERL association was considered as one primary diagnosis. Due to the presence of limb anomalies and anal stenosis and the observation of bilateral triphalangeal thumbs in the father, Townes-Brocks syndrome was the other primary diagnosis. The absence of the left radius however was considered as an exclusion criterion for SALL1 analysis since such malformations have never been observed with SALL1 mutations (Kohlhase, unpublished results). SALL4 analysis revealed the nonsense mutation c.496C > T (Q166X; exon 2) in the index patient and the father (fig lA).

In family 2 (figs 1 and 3 ), a couple presented to genetic counselling during pregnancy after previous birth of a child diagnosed with Holt-Oram syndrome, based on the presence of typical radial malformations and a VSD. Family history (see case reports) revealed dominant inheritance of the condition with the father of the child, his mother, brother, and niece being similarly affected with radial malformations. SALL4 analysis was considered based on the presence of a kidney position anomaly, thought to be distinctive for SALL4 mutations as opposed to TBX5 mutations. For analysis a sample was only available from the father of the boy. Direct sequencing suggested a heterozygous frameshift mutation, which was confirmed by sequencing of subcloned PCR fragments to be c.899-900delCTinsG (exon 2; fig 1B).

Family 3 (fig 1) has been reported as a classical example of acro-renal-ocular syndrome. ${ }^{12}$ In this family, a mother and two of her adult children are affected with radial anomalies of the upper limbs as well as eye anomalies of different severity. Notably, none of the affected persons has a Duane anomaly. In the patient with the most severe eye malformations, SALL4 analysis detected the mutation c.2477delC (exon 3 ) in a heterozygous state (fig IC). Unfortunately, further family members were not available for study.

In family 4, a patient with sporadic Okihiro syndrome sought DNA analysis to confirm the clinical diagnosis (fig 1D). He was found to carry the heterozygous mutation c.2491C > T (R831X; exon 3). The parents were not available for examination.

Finally, SALL4 mutation analysis was performed in family 5 (figs 1 and 3). Here, mother and daughter were initially diagnosed as having Holt-Oram syndrome but the diagnosis was changed to acro-renal-ocular syndrome based on the 
2477delC

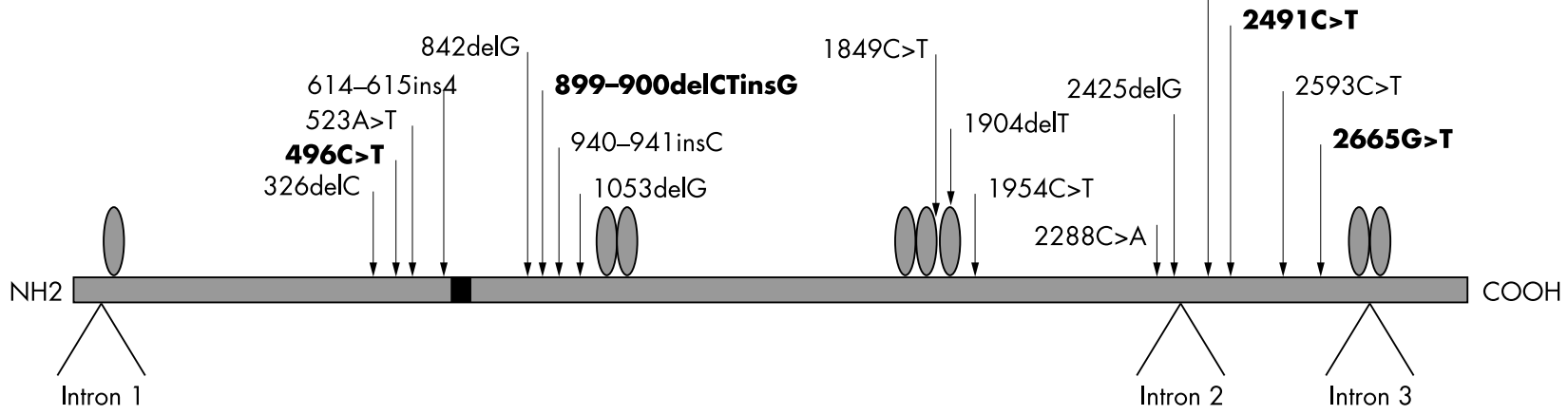

Figure 2 Schematic representation of the SALL4 gene/protein and localisation of all mutations identified. Zinc finger motifs are shown as oval symbols. Mutations reported in this paper are shown in bold, and previously identified mutations in plain font. The black box represents the conserved Glu-rich domain thought to mediate interaction with other SALL proteins. ${ }^{14}$ Note that the mutations are distributed over exons 2 and 3.
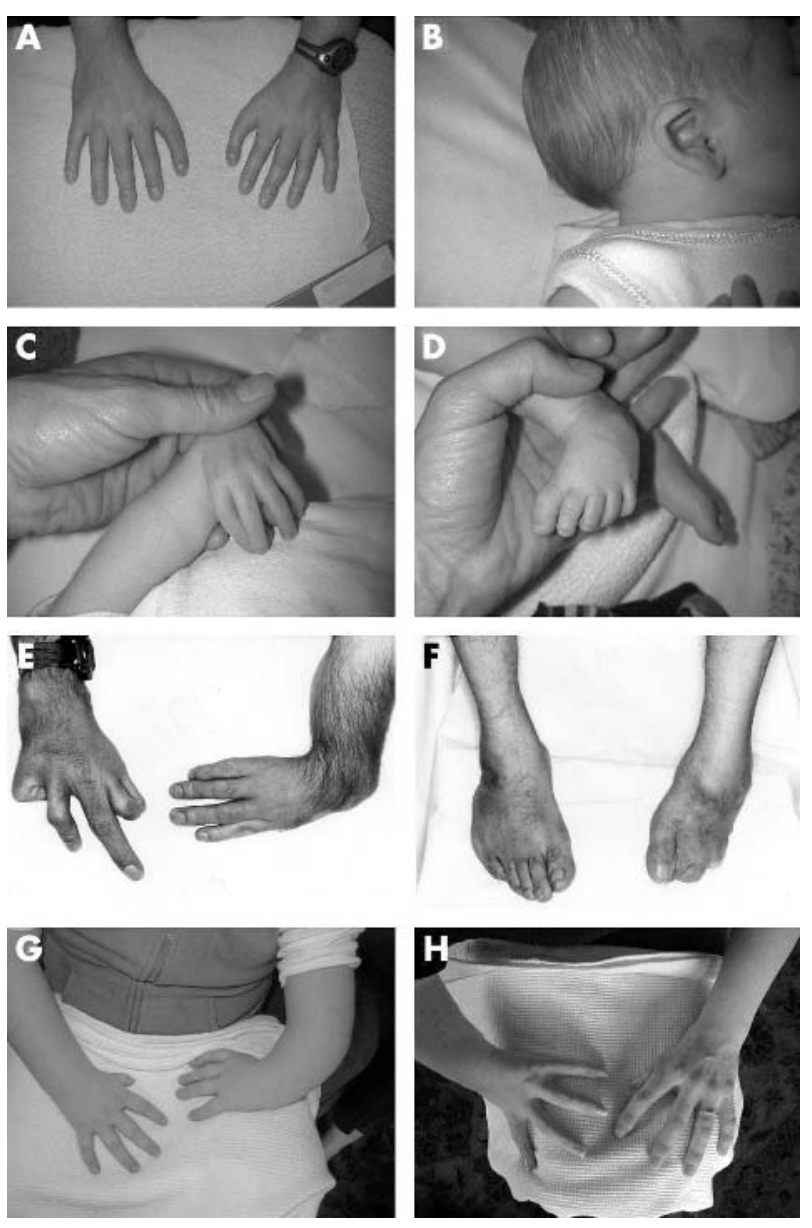

Figure 3 Phenotypic features of patients. (A) Bilateral triphalangeal thumbs of the father in family 1 . (B-D) Pictures of his son, showing a mildly dysplastic right ear (B) with a somewhat "turned over" superior helix (left ear similar, not shown), radial deviation of left hand with aplasia of thumb (right thumb hypoplastic) and radius on this side, and (D) talipes of the left foot (also on the right side). (E) Hand malformations of patient II.2 (family 2) with radial deviation of the hand and aplasia of thumb and radius on the left, and hypoplastic thumb with contractures of fingers II, IV, and V on the right side. (F) Foot and lower leg malformations of the same man with bilateral club foot and shortening of the left leg. Note partial syndactyly II/III and III/IV. (G) Hand

malformations of patient II. 1 (family 5) include radial deviation of the left hand with aplasia of thumb with hypoplasia of radius and ulna on the left, and hypoplastic thumb on the right side, while her mother I.1 (H) has aplasia of the right thumb with ipsilateral hypoplasia of radius and ulna, and a hypoplastic left thumb. observation of kidney anomalies. Here, we found the heterozygous mutation 2665G $>$ T (E889X; exon 3) in the mother and the daughter but not in the unaffected father (fig $\mathrm{lE}$ ).

\section{DISCUSSION}

In this report we present five novel SALL4 mutations (figs 1 and 2), adding to a total of 17 clearly disease causing SALL4 mutations. The V752M "mutation"' is not included here as a true mutation because Valine 754 (the wrong designation V752M should be corrected to V754M (c.2260G >A) according to the SALL4 CDNA sequence) is not conserved between mouse Sall4 and human SALL4, and the authors could not demonstrate segregation with the phenotype. Of the 17 mutations, 13 are located within exon 2, and four in exon 3 (fig 2). No mutation has been found elsewhere in the gene so far. Interestingly, the mutations seem rather evenly distributed over the gene, in contrast to the situation of SALL1 mutations in Townes-Brocks syndrome. Here, about $75 \%$ of mutations have been found in a hotspot region between the coding sequences for the aminoterminal $\mathrm{C}_{2} \mathrm{HC}$ zinc finger and the most aminoterminal double zinc finger domain. ${ }^{3}$ While this peculiar hotspot has led to the idea and proof in a mouse model that SALL1 mutations might have a dominantnegative effect ${ }^{13}$ rather than leading to SALL1 haploinsuffiency as initially assumed, ${ }^{2}$ it remains to be shown if the rather homogeneous distribution reflects a different pathogenetic action of SALL4 mutations.

Our results further support the suggestion that acro-renalocular syndrome and Okihiro syndrome are allelic diseases. ${ }^{10}$ Here we show that a typical SALL4 frameshift mutation (c.2477delC) most likely causes the phenotype of limb, eye, and renal anomalies in one of the few families reported to delineate the syndrome. Although we could not analyse more affected family members, there is no doubt that this deleterious mutation is responsible for the limb and kidney anomalies. It would however have been interesting to rule out the postaxial polydactyly in some otherwise unaffected family members being unrelated to the SALL4 mutation. Importantly, the patient analysed is to our knowledge the only patient with acro-renal-ocular syndrome reported to have such severe eye malformations (coloboma, microphthalmia with microcornea, nystagmus, and cataract). Neither his sister, who has much more severe limb malformations, nor his mother have similar eye defects. Notably, none of the family members has a Duane anomaly. This, however, is present in both patients of family 5 , who also have kidney anomalies but no structural eye defects. Out data presented here suggest that acro-renal-ocular syndrome and Okihiro syndrome are truly allelic in most instances. If a Duane 
anomaly is accepted as part of acro-renal-ocular syndrome, it seems that most patients with SALL4 mutations could carry either this diagnosis or a diagnosis Okihiro syndrome. Our own observations suggest that position anomalies of the kidneys are quite common with SALL4 mutations, and it seems that they are often overlooked or have been so in the past when a diagnosis of Holt-Oram syndrome seemed evident from observation of typical limb anomalies. Apart from this, our data from family 1, 2, and 3 further suggest that Duane anomaly is not always present with SALL4 mutations. Therefore, if Holt-Oram syndrome is considered as a diagnosis in a child, we strongly recommend renal ultrasound in addition to an ophthalmological examination in order to rule out a disease caused by SALL4 mutations. Our data also show that some patients diagnosed with VACTERL association might suffer from Okihiro syndrome instead. Our impression is that the absence/presence of tracheo-oesophageal malformations might be the crucial criterion to differentiate between the two entities.

New phenotypic features were also observed in the patients reported here. Most notably, the index patient in family 1 has a severe heart defect (tetralogy of Fallot). Although more data are required to investigate if this is a rare event, the severity of a heart defect does not seem a good criterion to differentiate between Holt-Oram and Okihiro syndromes. Two patients, one of family 1 and one of family 2, showed bilateral club feet/talipes at birth, and the patient in family 1 has sacrovertebral fusion. The patient of family 4 has slit-like external ear canals and bilateral epicanthic folds, confirming previous assumptions that anomalies of the face and the auditory ducts are true manifestations of SALL4 mutations. ${ }^{10}$ In general, it appears that quite a few phenotypic features are occasional consequences of SALL4 mutations. Results from studies of further families as well as careful clinical examination of all affected family members within a given family is required to obtain a more objective picture of the occurrence rates of the phenotypic manifestations of SALL4 mutations reported so far.

In summary, our findings suggest that acro-renal-ocular and Okihiro syndrome are both part of a phenotypic spectrum caused by SALL4 mutations and may be indistinguishable in most instances since renal anomalies are often found in patients with Okihiro syndrome. Severe structural eye defects might also be caused by SALL4 mutations but results from further patients similarly affected are required to confirm this hypothesis.

Together with this report, in total 17 different SALL4 mutations have been described. ${ }^{45}{ }^{10}$ These are two small insertions (c.940-94linsC, c.614-615ins4), six deletions (c.326delC, c.842delG, c.1053delG, c.1904delT, c.2425delG, c.2477delC), one deletion/insertion (c.899-900delCTinsG) and eight nonsense mutations (c.496C $>\mathrm{T}$, c.523A $>\mathrm{T}$, c. $1849 \mathrm{C}>\mathrm{T}$, c. $1954 \mathrm{C}>\mathrm{T}$, c. $2288 \mathrm{~T}>\mathrm{A}$, c. $249 \mathrm{lC}>\mathrm{T}$, c. $2593 \mathrm{C}>\mathrm{T}$, c. $2665 \mathrm{G}>\mathrm{T}$ ). Although we have described five novel mutations it is still not possible at the present time to correlate the severity of the phenotype with mutation position, the strongest argument being that the mutation c.2593C $>$ T may cause either a mild or a severe phenotype. ${ }^{4}{ }^{10}$

\section{ACKNOWLEDGEMENTS}

We would like to thank the families for their participation, Ulrike Dohrmann for subclone sequencing, and Manuela Liebers for technical assistance.

\section{Authors' affiliations}

W Borozdin, Institut für Humangenetik, Universität Göttingen, Göttingen, Germany
M J Wright, Institute of Human Genetics, International Centre for Life, Central Parkway, Newcastle-upon-Tyne, UK

R C M Hennekam, Departments of Pediatrics and Clinical Genetics, Academic Medical Center, University of Amsterdam, Amsterdam, The Netherlands

M C Hannibal, Division of Genetics and Development, Department of Pediatrics, University of Washington, Seattle, WA, USA

Y J Crow, Department of Clinical Genetics, St James's University Hospital, Leeds, UK

T E Neumann, Institut für Humangenetik, Universität Münster, Münster, Germany

W Borozdin, J Kohlhase, Institut für Humangenetik und Anthropologie, Universität Freiburg, Freiburg, Germany

This work was funded by the Wilhelm-Sander-Stiftung (grant 98.075.2 to JK).

Conflict of interest: none declared.

GenBank accession numbers: SALL4 mRNA, NM_020436; genomic contig NT_011362.

Correspondence to: Dr J Kohlhase, Institut für Humangenetik und Anthropologie, Universität Freiburg, Breisacher Str. 33, 79106

Freiburg, Germany; jkohlha@ukl.uni-freiburg.de

Revised version received 25 March 2004

Accepted for publication 26 March 2004

\section{REFERENCES}

1 Kühnlein RP, Frommer G, Friedrich M, Gonzalez-Gaitan M, Weber A Wagner-Bernholz JF, Gehring W, Jäckle H, Schuh R. spalt encodes an evolutionary conserved zinc finger protein of novel structure which provides homeotic gene function in the head and tail region of the Drosophila embryo. EMBO J 1994:13:168-79.

2 Kohlhase J, Wischermann A, Reichenbach H, Froster U, Engel W. Mutations in the SALL1 putative transcription factor gene cause Townes-Brocks syndrome. Nat Genet 1998;18:81-3.

3 Kohlhase J. SALL 1 mutations in Townes-Brocks syndrome and related disorders. Hum Mutat 2000;16:460-6.

4 Al-Baradie R, Yamada K, St Hilaire C, Chan WM, Andrews C, Mclntosh N, Nakano M, Martonyi EJ, Raymond WR, Okumura S, Okihiro MM, Engle EC. Duane Radial Ray Syndrome (Okihiro syndrome) maps to $20 \mathrm{q} 13$ and results from mutations in SALL4, a new member of the SAL family. Am J Hum Genet 2002;71:1195-9

5 Kohlhase J, Heinrich $M$, Schubert L, Liebers $M$, Kispert A, Laccone F, Turnpenny P, Winter RM, Reardon W. Okihiro syndrome is caused by SALL4 mutations. Hum Mol Genet 2002;1 1:2979-87.

6 Kohlhase J, Schuh R, Dowe G, Kühnlein RP, Jäckle H, Schroeder B, SchulzSchaeffer W, Kretzschmar HA, Köhler A, Müller U, Raab-Vetter M, Burkhardt E, Engel W, Stick R. Isolation, characterization, and organ-specific expression of two novel human zinc finger genes related to the Drosophila gene spalt. Genomics 1996;38:291-8.

7 Kohlhase J, Hausmann S, Stojmenovic G, Dixkens C, Bink K, SchulzSchaeffer W, Altmann M, Engel W. SALL3, a new member of the human spaltlike gene family, maps to 18q23. Genomics 1999;62:216-22.

8 Okihiro MM, Tasaki T, Nakano KK, Bennett BK. Duane syndrome and congenital upper-limb anomalies. A familial occurrence. Arch Neurol 1977;34:174-9.

9 Brassington $A M$, Sung SS, Toydemir RM, Le T, Roeder AD, Rutherford AE, Whitby FG, Jorde LB, Bamshad MJ. Expressivity of Holt-Oram syndrome is not predicted by TBX5 genotype. Am J Hum Genet 2003;73:74-85.

10 Kohlhase J, Schubert L, Liebers M, Rauch A, Becker K, Mohammed SN, Newbury-Ecob R, Reardon W. Mutations at the SALL4 locus on chromosome 20 result in a range of clinically overlapping phenotypes, including Okihiro syndrome, Holt-Oram syndrome, acro-renal-ocular syndrome, and patients previously reported to represent thalidomide embryopathy. J Med Genet 2003;40:473-8.

11 Becker K, Beales PL, Calver DM, Matthiis G, Mohammed SN. Okihiro syndrome and acro-renal-ocular syndrome: clinical overlap, expansion of the phenotype, and absence of PAX2 mutations in two new families. J Med Genet 2002;39:68-71.

12 Aalfs CM, van Schooneveld MJ, van Keulen EM, Hennekam RCM. Further delineation of the acro-renal-ocular syndrome. Am J Med Genet 1996;62:276-81.

13 McLeskey Kiefer S, Ohlemiller KK, Yang J, McDill BW, Kohlhase J, Rauchman M. Expression of a truncated Sall 1 transcriptional repressor is responsible for Townes-Brocks syndrome birth defects. Hum Mol Genet 2003; 12:2221-7.

14 Sweetman D, Smith T, Farrell ER, Chantry A, Münsterberg A. The conserved glutamine rich region of chick csall and csal 3 mediates protein interactions with other spalt family members. Implications for Townes-Brocks syndrome. J Biol Chem 2003;278:6560-6. 